\title{
Uso de ingredientes provenientes de OGM em rações e seu impacto na produção de alimentos de origem animal para humanos
}

\author{
Anibal E. Vercesi ${ }^{1}$, Felipe G. Ravagnani ${ }^{1}$, Luciana Di Ciero ${ }^{2}$ \\ ${ }^{1}$ Departamento de Patologia Clínica, Faculdade de Ciências Médicas, UNICAMP. \\ 2 Amyris Crystalsev Biocombustíveis Ltda., Campinas, SP.
}

RESUMO - Desde os primórdios o homem buscou selecionar as plantas alimentícias para maior produtividade. O conhecimento da estrutura do DNA permitiu que a engenharia genética se desenvolvesse consideravelmente fornecendo ferramentas para a realização de alterações específicas no genoma. Os produtos destas alterações são denominados transgênicos ou organismos geneticamente modificados (OGM) e apresentam alto potencial de aplicação em diversas áreas da atividade humana como: agricultura, medicina, saúde, produção e processamento de alimentos, produção bioquímica, controle de doenças e biorremediação. Atualmente, as plantas transgênicas, oriundas da tecnologia do DNA recombinante, trouxeram novas variedades já cultivadas em mais de 100 milhões de hectares em 23 países, incluindo o Brasil, onde 8 variedades já foram aprovadas pela Comissão Técnica Nacional de Biossegurança (CTNBio). Esse método de melhoramento genético facilitou a introdução de características desejáveis em plantas, como resistência a estresses bióticos e abióticos e otimização da composição de alguns nutrientes essenciais à saúde animal e humana. Enquanto estes avanços da biotecnologia abrem novas perspectivas para a solução de problemas em áreas como a agricultura, a liberação de transgênicos para uso na natureza traz preocupações quanto a possíveis problemas de natureza ecológica e para a saúde humana e animal. Estas preocupações deram origem à criação de agências governamentais para controlar o uso desta tecnologia e regulamentar a segurança dos alimentos transgênicos e seus derivados. Até o momento, os estudos científicos mostram que os transgênicos liberados comercialmente são tão seguros ou mais ao meio ambiente e a saúde animal e humana que os convencionais.

Palavras-chave: organismos geneticamente modificados, saúde humana e animal, segurança alimentar, transgênicos em rações

\section{Use of ingredients from OGM in feed and its impact on the production of food of animal origin for human}

\begin{abstract}
From the origins the man has looked and selected vegetables with nutritive value for larger productivity. The knowledge of DNA structure allowed genetic engineering to develop and supplying tools for the accomplishment of specific alterations in the genome considerably. The products of these alterations are denominated transgenic or organisms genetically modified (OGM) and they present high application potential in several areas of the human activity as: agriculture, medicine, health, production and processing of foods, biochemical production and control of diseases. Nowadays, transgenic plants, originating from technology of the DNA recombinant, brought new varieties cultivated already in more than 100 million hectares in 23 countries, including Brazil, where 8 varieties were already approved for the National Technical Commission of Biosafety (CTNBio). That method of genetic improvement facilitated the introduction of desirable characteristics in plants, such as, resistance to biotic and non-biotic stress and optimization of the composition of some essential nutrients to the animal and human health. While these progresses of the biotechnology open new perspectives for the solution of problems in areas as the agriculture, the transgenic liberation for use in the nature brings concerns as for possible problems of ecological nature and for the human and animal health. These concerns brought the creation of government agencies to control the use of this technology and to regulate the safety of transgenic foods and yours derived. Until the moment, the scientific studies show that the transgenic liberated commercially are so safe or more to the environment and the animal and human health that the conventional ones.
\end{abstract}

Key Words: food safety, human and animal health, organisms genetically modified, transgenic in rations

\section{Introdução}

Um dos principais problemas da atualidade refere-se à disponibilidade e acesso da população mundial a alimentos.
Segundo a FAO (2004) a fome e a desnutrição matam mais de cinco milhões de crianças todos os anos. Estima-se que para alimentar a população da África em 2050, este continente terá que aumentar a sua produção de alimentos em 200 por 
cento, a Ásia em 69 por cento, a América Latina e Caribe em 80 por cento e a América do Norte em 30 por cento, de acordo com um estudo da FAO e do UNFPA (1996). Uma das alternativas mais viáveis e utilizadas para aumentar a produtividade e a produção de alimentos é a tecnologia aplicada à agricultura.

Desde os primórdios o homem buscou selecionar as plantas alimentícias para maior produtividade, sabor, adaptação ao clima, etc. Assim, a agricultura atingiu níveis surpreendentes, pois, enquanto a caça exigia 2500 ha para alimentar uma pessoa, uma agricultura com tecnologia moderna consegue produzir alimentos suficientes para alimentar 4000 pessoas em 250 ha (Stork \& Teague, 1952; Borlaug, 1972). Todo esse avanço foi obtido graças ao desenvolvimento de tecnologia aplicada à produção vegetal, incluindo o melhoramento genético. Com a postulação das leis mendelianas em 1900 e o subseqüente desenvolvimento da Genética, o melhoramento das plantas passou a ser cada vez mais eficiente permitindo aumentar a produtividade agrícola e melhorar a proteção do meio ambiente.

Organismos geneticamente modificados (OGM) ou transgênicos

Os termos transgênicos ou organismos geneticamente modificados (OGMs) referem-se a plantas, animais ou microrganismos que receberam genes de outros organismos no seu genoma para expressar características desejadas do organismo doador. Isso se tornou possível graças ao desenvolvimento datecnologia do DNA recombinante que abriu a possibilidade de isolamento e clonagem de genes de bactérias, vírus, plantas e animais seguidos da possibilidade de introdução e expressão dos mesmos em qualquer outro organismo. Desta forma, a barreira do cruzamento entre espécies e até entre diferentes reinos foi rompida, trazendo inúmeras possibilidades para o melhoramento de plantas, animais e microrganismos.

A transformação genética de vegetais permite a introdução de genes específicos no genoma de cultivares comerciais e permite o fluxo de genes para plantas, que não poderiam obtê-los através de cruzamentos sexuais ou outras técnicas convencionais. A grande vantagem para o melhorista de plantas é a precisão da técnica, já que ele consegue inserir somente a característica planejada, sem trazer outros genes indesejáveis.

Aplicações - A tecnologia do DNA recombinante para a obtenção de OGMs pode ser utilizada em várias áreas da atividade humana, incluindo a agricultura. As plantas transgênicas produzidas, até o momento, têm como objetivos principais a melhoria de resistência aos estresses bióticos e abióticos, bem como a otimização de composição de alguns nutrientes essenciais à saúde humana e animal. Dentre as aplicações mais usadas destaca-se a resistência a insetos e a tolerância a herbicidas. Estas e outras aplicações na agricultura encontram-se listadas na Tabela 1.

Do ponto de vista do melhoramento genético, é importante salientar que os métodos convencionais e a transgenia não são mutuamente excludentes, ao contrário, são complementares, e é neste contexto que devem ser considerados. Na verdade, todo o progresso genético para produtividade e demais atributos quantitativos, até cerca de 20 anos atrás, foi obtido por métodos convencionais. A transgenia apenas incorporou nas variedades superiores um ou poucos genes responsáveis por características específicas que conferem certas vantagens adicionais, como resistência a insetos pragas, herbicidas e melhoria da composição nutricional.

Segurança dos alimentos contendo ingredientes de OGMs - Os grãos e silagens de plantas transgênicas têm sido largamente utilizados na alimentação animal com amplas vantagens quando comparado às plantas convencionais. Entre as vantagens estão maior produtividade e melhor qualidade do alimento no que se refere aos baixos índices de contaminação por agrotóxicos e por micotoxinas, bem como melhor composição nutricional. Enquanto estes avanços da biotecnologia abrem novas perspectivas para a solução de problemas em áreas como a agricultura, a liberação de transgênicos, para uso na natureza, traz novas abordagens de estudos quanto a possíveis problemas de natureza ecológica e para a saúde humana e animal. Estas abordagens deram origem à criação de agências governamentais para controlar o uso desta tecnologia e regulamentar a segurança dos alimentos transgênicos e seus derivados. Nos Estados Unidos isto está a cargo das agências: United States Department of Agriculture (USDA), Environmental Protection Agency (EPA), and Food and Drug Administration (FDA). No Brasil, a Comissão Técnica Nacional de Biossegurança (CTNBIO) é o órgão técnico colegiado responsável pela avaliação de biossesgurança de todas as atividades envolvendo OGMs.

Uso de ingredientes derivados de transgênicos na produção de ração para animais - Plantas geneticamente modificadas e seus derivados, bem como enzimas de microrganismos geneticamente modificados, são amplamente usados na preparação de rações animais. Cerca de 600 milhões de toneladas de rações preparadas a partir de milho, algodão, soja e canola transgênicos foram usadas 
Tabela 1 - Lista de culturas agrícolas transgênicas e as características introduzidas (Adaptado do banco de dados da AGBIOS; http:// www.agbios.com)

\begin{tabular}{|c|c|}
\hline Cultura agrícola & Característica introduzida \\
\hline Alfalfa & Tolerância ao herbicida Glifosato \\
\hline Canola & $\begin{array}{l}\text { Tolerância ao herbicida Oxinil (bromoxinil e ioxinil), ao herbicida } \\
\text { glifosato, glufosinato de amônio, imidazolinona (imazethapir); modificações no conteúdo } \\
\text { de ácidos graxos (altos níveis de ácido laurato, ácido oléico, baixo conteúdo de ácido } \\
\text { linoléico e produção de ácido mirístico) }\end{array}$ \\
\hline Cravos & $\begin{array}{l}\text { Melhoria no tempo de prateleira devido a redução do acúmulo de etileno; } \\
\text { tolerância ao herbicida Sulfonilurea (triasulfon e metil metsulfuron); modificação na cor das flores }\end{array}$ \\
\hline Chicória & Tolerância ao herbicida glufosinato de amônio \\
\hline Algodão & $\begin{array}{l}\text { Resistência a insetos Lepdópteras e tolerância aos herbicidas Oxinil (bromoxinil e ioxinil), } \\
\text { Sulfonilurea, glifosato e glufosinato de amônio }\end{array}$ \\
\hline Grama "Creeping Bentgrass" & Tolerância ao herbicida glifosato \\
\hline Linho & Tolerância ao herbicida Sulfonilurea (especificamente triasulfon e metil metsulfuron) \\
\hline Lentilhá & Tolerância ao herbicida imidazolinona (imazethapir) \\
\hline Milho & $\begin{array}{l}\text { Tolerância aos herbicidas glifosato; imidazolinona; glufosinato de amônio; Cicloexanona (setoxidin); } \\
\text { e resistência a insetos do gênero Lepdoptera (lagartas) e Coleoptera; macho esterilidade; } \\
\text { modificação na amilase para produção de etanol }\end{array}$ \\
\hline Melão & Atraso no amadurecimento \\
\hline Mamão & Resistência a vírus \\
\hline Ameixa & Resistência a vírus \\
\hline Batata & Resistência a insetos Coleopteros e a vírus \\
\hline Arroz & Tolerância ao herbicida imidazolinona (imazethapir) e ao glufosinato de amônio; \\
\hline Soja & $\begin{array}{l}\text { Tolerância aos herbicidas glifosato; imidazolinona; glufosinato de amônio; e modificação no } \\
\text { conteúdo de ácidos graxos (alta expressão de ácido oléico e baixo conteúdo de ácido linoléico) }\end{array}$ \\
\hline Abóbora & Resistência a vírus \\
\hline Beterraba & Tolerância aos herbicidas glifosato; e glufosinato de amônio \\
\hline Girassol & Tolerância ao herbicida imidazolinona \\
\hline Tabaco & Tolerância ao herbicida Oxinil; redução de nicotina \\
\hline Tomate & $\begin{array}{l}\text { Aumento do tempo de prateleira (amadurecimento tardio); resistência a insetos } \\
\text { Lepdopteras (lagartas); atraso do amolecimento. }\end{array}$ \\
\hline Trigo & Tolerância aos herbicidas Imidazolinonas e ao glifosato. \\
\hline
\end{tabular}

no ano de 2002 (James, 2002). Atualmente, esta produção deve ter aumentado consideravelmente uma vez que o cultivo de OGM dobrou neste período. Estima-se que em $2008,70 \%$ da área global com soja, 30\% com canola, $46 \%$ com algodão e $24 \%$ com milho sejam geneticamente modificados (James, 2008).

A avaliação de segurança destes alimentos à saúde humana e animal é feita examinando-se: composição química, características moleculares e nutricionais, alergenicidade, toxicidade, etc., comparando-as com a contraparte convencional. São alvos da avaliação: a saúde dos animais que ingerem a ração, dos consumidores que ingerem os produtos animais derivados, a segurança dos trabalhadores que manipulam estes produtos e outros aspectos ambientais resultantes do emprego do alimento animal, sempre comparando os resultados com a contraparte convencional.

As preocupações principais quanto ao uso de produtos geneticamente modificados em rações são: 1) possibilidade de efeitos adversos no caso do DNA modificado da planta ser transferido para a cadeia alimentar, 2) possibilidade de transferência de genes marcadores de resistência a antibióticos, usados no processo de transformação, para bactérias do trato digestivo animal e, posteriormente, para bactérias patogênicas ao homem e, 3) efeitos indesejáveis dos derivados de microorganismos modificados.

Com respeito à transferência de DNA para a cadeia 
alimentar, tem sido observado que apesar do DNA modificado muitas vezes ser resistente ao processamento e permanecer intacto na ração, sua digestão ocorre através da ação de nucleases presentes na boca, pâncreas e secreções intestinais. Em ruminantes ocorre degradação adicional por ação microbiana e processos físicos. A eficiência da degradação digestiva em humanos e animais é também evidenciada pela longa história do consumo seguro de DNA pelos mamíferos. A digestão do DNA transgênico não é diferente uma vez que é composto pelos mesmos blocos construtivos que o convencional. Uma estimativa da quantidade de ingestão de DNA recombinante de milho transgênico indica o seguinte: a percentagem de DNA recombinante no genoma de Zea mays é de aproximadamente $0,00022 \%$. Isso significa que, com o conteúdo de $1,496 \mu \mathrm{g}$ de DNA/g de milho, o consumo per capita do DNA recombinante é no máximo de $0,00033 \mu \mathrm{g} / \mathrm{g}$ (Lassek \& Montag, 1990). Assim, uma vaca de $600 \mathrm{~kg}$ ingere, por dia, na sua ração normal, cerca de $600 \mathrm{mg}$ de DNA total (Beever \& Kemp, 2002). Se todo o milho da formulação for GM, a ingestão de DNA recombinante seria de $1,5 \mathrm{mg}$, ou seja, de $0,00024 \%$ do total ingerido por dia e ainda sujeito à degradação intestinal.

Outros estudos demonstram que é praticamente impossível ocorrer transferência de resistência a antibióticos dos genes marcadores, usados na produção de plantas GM, para microrganismos dos animais alimentados com a ração e, dali, para bactérias patogênicas ao homem (Benveniste \& Davies, 1973; Bevan et al., 1983; Chambers \& Heritage, 2004).

Tem sido também demonstrado que são seguros a saúde humana e animal os produtos derivados de microorganismos geneticamente modificados. Assim, pães, doces e salgados, massas, mistura para bolos, biscoitos e produtos de confeitarias podem conter enzimas produzidas por microorganismos geneticamente modificados. Há queijos e leites fermentados por enzimas derivadas de microorganismos geneticamente modificados (MGMs), como a catalase e a quimosina. Frios diversos (salame, presunto etc.) podem conter soja transgênica em sua composição, além de enzimas ou os próprios microorganismos geneticamente modificados. Algumas carnes contêm enzimas proteolíticas geradas por MGMs com função de amaciamento, ou peptídeos antibacterianos, produzidos por bactérias GMs, empregados para protegêlas de eventual contaminação microbiológica. A pectinase proveniente de MGMs é usada para clarificar sucos e geléias. Há realçadores de sabor, edulcorantes e amidos produzidos por OGMs que são usados em molhos, salgados e outros alimentos. Detergentes e sabões em pó podem conter enzimas produzidas por MGMs. As indústrias de papel e celulose, de couro e jeans usam enzimas derivadas de MGMs para diversas finalidades. Apesar desta grande convivência com produtos contendo derivados de MGMs, durante as últimas duas décadas, não foi constatada nenhuma mudança em termos de saúde pública no mundo, que pudesse ser atribuída ao consumo desses produtos. Manifestações e revisões científicas recentes de especialistas e entidades científicas importantes confirmam estas observações bem como os resultados de estudos anteriores (Lajolo \& Nutti, 2003; Chassy et al., 2004; ILSI, 2004; USP, 2005; Lajolo \& Di Ciero, 2006 ).

As mesmas dimensões aplicam-se às proteínas recobinantes expressas pelos transgenes. Dado à sua pequena concentração e estabilidade aos agentes térmicos e químicos e as ações das enzimas digestivas, a ocorrência de qualquer efeito indesejável é bastante improvável, como descrito abaixo. Noventa por cento das plantas transgênicas cultivadas no mundo e $100 \%$ no Brasil expressam proteínas que conferem resistência a insetos ou herbicidas (James, 2008). As proteínas expressas nos transgênicos resistentes a insetos apresentam toxicidade específica contra certos lepidópteros-praga, mas não existem evidências de que estas proteínas tenham efeitos nocivos à saúde de seres humanos e animais (Okunuki et al., 2002; Donkin et al., 2003; Ipharraquerre et al., 2003; Shimada et al., 2003; Taylor et al., 2004; Sanden et al., 2005; Taylor et al., 2005; Hammond et al., 2006; Manetti et al., 2006; Nakajima et al., 2007). Igualmente seguras em termos de toxicidade a humanos e animais são as proteínas que conferem tolerância ao glufosinato de amônio (Cromwell et al., 2005.; Wehrmann et al, 1996; Calsamiglia et al., 2007; Castillo et al., 2004) e ao glifosato (Erickson et al., 2003; Taylor et al., 2004; Taylor et al., 2005). Estes estudos demonstram ausência de diferenças significativas entre as características alimentares e valor nutricional das plantas modificadas com as proteinas recombinantes e as equivalentes convencionais. Além da detecção da enzima especificamente induzida pelo gene inserido, não se detectou a presença de qualquer substância tóxica ou alergênica. As análises comprovam ainda a rápida degradação da proteína mutante no suco gastro-intestinal.

Estudos sobre alimentação de bovinos, suínos e aves com rações contendo soja e milho resistentes a insetos e herbicidas, mostraram ausência de efeitos adversos nos animais alimentados com produtos destes transgênicos (Donkin et al., 2003; Ipharraquerre et al., 2003; Castillo et al., 2004; Cromwell et al., 2005; Calsamiglia et al., 2007). Os 
parâmetros avaliados incluíram composição nutricional, peso vivo, ingestão alimentar, conversão alimentar, produção de leite, composição do leite, fermentação no rúmen, taxa de crescimento e características da carcaça. Observou-se ligeira melhoria na taxa de conversão alimentar para animais alimentados com milho resistente a insetos, possivelmente devido às menores concentrações de micotoxinas, que são anti-nutrintes resultantes do ataque de insetos (MacKenzie \& McLean, 2002).

Um estudo realizado na Universidade de Illinois (Ipharraguerre et al., 2003) analisou o desempenho de vacas leiteiras alimentadas com silagem e grãos de milho tolerante a glifosato (evento NK 603), durante um período de 28 dias, comparando com vacas alimentadas com um híbrido não transgênico da mesma linhagem e dois outros híbridos disponíveis comercialmente. Analisou-se: 1) a composição química dos grãos e da silagem; 2) a quantidade de alimento consumido pelos quatro grupos e, 3) a produção e composição do leite. Os resultados mostraram que a composição química dos grãos e da silagem do milho transgênico foi substancialmente equivalente aos outros três híbridos usados, bem como não houve diferenças significativas na produção e composição do leite produzido pelos quatro grupos experimentais. Estes resultados estão de acordo com outras pesquisas mostrando que o desenvolvimento e a composição da carne de aves e porcos alimentados com milho tolerante a glifosato foram equivalentes a de animais controles (Gaines et al., 2001; Stanisiewski et al., 2001).

Estes estudos realizados com animais de grande porte, como neste caso do estudo com bovinos de leite, não visam detectar o efeito da nova proteína sobre órgãos específicos dos animais, mas sim sobre a saúde geral do animal e sobre a sua capacidade de seguir produzindo o alimento para o qual ele se destina de forma segura. Os efeitos medidos são geralmente sobre a ingestão de matéria seca e de grãos ou rações; produção e qualidade do leite (porcentagem de gordura, proteínas, lactose, sólidos nãogordurosos e N-uréia); condições corporais; e presença das proteínas recombinantes no leite. Os resultados da literatura, em estudos usando silagem e grãos de todos os transgênicos usados até o momento, não tem mostrado diferenças estatisticamente significativas na ingestão de alimento, no rendimento e composição do leite, assim como na condição corporal dos animais alimentados com ingredientes derivados de OGM em comparação com animais alimentados com ingredientes das plantas convencionais (Gaines et al., 2001; Stanisiewski et al., 2001; Ipharraguerre et al., 2003; Taylor et al., 2005).
As principais proteínas recombinantes presentes nas plantas usadas para produção de ração, até o momento, possuem histórico de consumo seguro por humanos e animais e estão caracterizadas abaixo.

Proteína CP4 EPSPS - A enzima CP4 EPSPS (CP4 5enolpiruvilchiquimato-3-fosfato sintase) é proveniente da Agrobacterium sp. cepa CP4, e foi identificada em uma varredura de microorganismos resistentes à ação da molécula do glifosato (OECD, 1999). O controle de plantas daninhas pelo herbicida glifosato ocorre pela inibição de enzima EPSPS produzida naturalmente pela planta. Esta enzima encontra-se em todas as partes verdes das plantas, em bactérias e fungos, e é importante para a produção de aminoácidos aromáticos essenciais. A inibição da EPSPS pelo glifosato bloqueia a produção destes aminoácidos, impedindo o crescimento e ocasionando, finalmente, a morte da planta. A proteína CP4 EPSPS da planta transgênica possui baixa afinidade pelo glifosato e quando a planta é tratada com este herbicida continua se desenvolvendo normalmente. A via biossintética de aminoácidos aromáticos não existe em animais, que por isso não são suscetíveis a esse tipo de efeito tóxico produzido por esse agente químico, sem excluir, obviamente, outros efeitos diretos ou indiretos.

A proteína EPSPS é considera ubíquita na natureza por estar presente em todas as plantas e em vários microorganismos (Levin \& Sprinson, 1964). Isso comprova sua biossegurança, uma vez que todos os organismos que se alimentam de plantas e/ou microorganismos são amplamente expostos às proteínas EPSPS. Ela é degradada rapidamente no sistema gastrintestinal de humanos e animais, conforme esperado para uma enzima metabolicamente lábil. Isso, associado ao seu modo de ação, à sua especificidade, à ausência de homologia com seqüências tóxicas e à ausência de toxicidade oral aguda em mamíferos, faz com que esta proteína não represente risco à saúde humana. Estudos com soja RR, já liberada comercialmente no Brasil, confirmam que a proteína CP4 EPSPS não causa alergia e neste aspecto é idêntica a soja convencional (Kim et al. 2006).

Estudos realizados com várias culturas como soja, algodão, canola, milho e beterraba, demonstram que a inserção do gene cp4 epsps e a expressão da proteína CP4 EPSPS tolerante ao glifosato não alteram os níveis de nutrientes e anti-nutrientes, inclusive dos produtos da via do ácido chiquímico, nas plantas tratadas e não tratadas com glifosato. Os valores para todos os componentes bioquímicos avaliados foram similares aos valores do controle convencional, ou estiveram dentro da faixa observada para variedades convencionais (Padgette et al., 
1996; Taylor et al., 1999; Nickson \& Hammond, 2002; Ridley et al., 2002). Os produtos da via do ácido chiquímico, como isoflavonas estrogênicas e seus glicosídeos, também foram medidos e demonstraram similaridade com os níveis observados nos grãos de soja não transgênicos (Duke et al., 2003).

Proteína NPTII - A proteína NPTII (neomicina fosfotransferase tipo II) é produzida por vários organismos procarióticos encontrados de forma ubíquita no meio ambiente tanto em habitats aquáticos e terrestres quanto na microflora intestinal humana e animal (Flavell et al., 1992). O gene nptII (que codifica a proteína NPTII), utilizado na geração do Algodão Roundup Ready® evento 1445, é derivado do transposon Tn5 de Escherichia coli (Beck et al., 1982; Bevan et al., 1983), que é uma enterobactéria presente na flora intestinal do homem. A enzima NPTII não é produzida normalmente em tecidos vegetais e, portanto, antibióticos aminoglicosilados sâo letais para as células vegetais. A expressão da proteína NPTII foi utilizada para seleção de células vegetais trasformadas, por conferir resistência aos aminoglicosídeos.

O modo de ação da proteína NPTII é bem caracterizado. A NPTII utiliza adenosina-trifosfato (ATP) para realizar a fosforilação do grupo 3'-hidroxil da porção aminohexose de antibióticos aminoglicosídicos (como a neomicina, a gentamicina A e as canamicinas A, B e C) inativando estes antibióticos (Beneveniste \& Davies, 1973; Schlüter \& Potrikus, 1997).

O histórico de exposição segura e o conhecimento preciso do mecanismo de ação da proteína NPTII são fatores que sustentam os aspectos de biossegurança para o meio ambiente, para o homem e animais. A proteína NPTII é degradada no sistema gastrintestinal de humanos e animais, o que, associado ao seu modo de ação, à sua especificidade e à ausência de homologia com seqüências tóxicas, faz com que ela não represente risco de toxicidade. Outro fator que contribui para a segurança alimentar da NPTII é que o co-fator ATP, necessário para a sua atividade, é instável em pH baixo como o do sistema digestivo. Assim, ainda que não degradada pelo suco gástrico, esta proteína não teria atividade biológica (Nap et al., 1992). A segurança desta proteína foi avaliada pelo FDA e pela Organização Mundial de Saúde, que concluíram que a NPTII é uma proteína segura para uso em alimentos.

Proteína cry $1 \mathrm{Ab}$ - O milho geneticamente modificado pela inserção do gene cry1 $\mathrm{Ab}$ de Bacillus thuringiensis resiste ao ataque por lagartas. A proteína Cry1Ab está expressa em todas as partes da planta notando-se a baixa expressão em grãos e pólen comparativamente as folhas. A proteína Cry1 Ab é uma delta-endotoxina, produzida pelo Bacillus thuringiensis que apresenta atividade específica sobre o sistema digestivo de algumas famílias de insetos. Para sua atividade a proteína deve ser ingerida pelos insetos, cujo pH alcalino estomacal é capaz de solubilizá-la. Sob a ação de proteases se transforma na forma ativada (núcleo tripsina resistente) que se liga a receptores específicos de alta afinidade presentes em insetos e ausentes em mamíferos. Estudos de toxicidade para aves, peixes e mamíferos com grãos de milho da linhagem MON810 com até $10 \%$ do peso de farelo de grãos integrais de milho na dieta não mostraram efeitos adversos ou tóxicos. Outros estudos demonstraram que a proteína Cry1Ab não apresenta característica de alergenicidade, e é degradada no aparelho gastro-intestinal de mamíferos. Animais alimentados com milho MON810 indicaram a equivalência do valor nutricional e eficiência de produção destes animais quando comparados com a variedade não transgênica (Taylor et al., 2003, 2004, 2005).

Proteína PAT - O gene bar inserido é uma réplica obtida de um trecho específico do DNA de Streptomyces hygroscopicus, um microorganismo não patogênico que ocorre naturalmente no solo. O gene bar codifica a enzima PAT (phosphinothricin acetyl transferase), uma acetil transferase específica ao substrato fosfinotricina (glufosinato de amônio-GA). A resistência ao glufosinato de amônia é devido aos seguintes fatores: a) o gene bar é expresso em todas as células da planta graças à ação do promotor 35S, constitutivo e ubíquo; b) a proteína codificada pelo gene bar, fosfinotricina acetil transferase (PAT), inativa por acetilação o glufosinato de amônio, composto que inibe a glutamina sintase e causa morte celular pelo acúmulo de amônia (Wehrmann et al., 1996). As plantas modificadas que expressam a proteína PAT apresentam o atributo que possibilita o uso seletivo, em pós-emergência, do herbicida biodegradável glufosinato de amônio para manejo de plantas daninhas, sem causar injúria à lavoura.

Testes de toxicidade e de mutagenicidade realizados com ratos e camundongos demonstraram que os animais que consumiram alimentos contendo esta proteína tiveram o ganho de peso e desenvolvimento normal. Nenhuma alteração histopatológica foi encontrada em vários órgãos analisados (Wang et al., 2000).

Propriedades alergênicas das proteínas recombinantes presentes nos OGMs - Os perfis bioquímicos destas proteínas recombinantes proporcionam uma base para a avaliação alergênica ao compará-las com alérgenos de proteínas conhecidas. A comparação da seqüência de aminoácidos de uma proteína introduzida com as seqüências de aminoácidos de alérgenos conhecidos pode resultar em 
um indicador útil de potencial alergênico. Uma homologia significativa é aquela que registra uma identidade de seqüência de 8 ou mais aminoácidos contíguos. Inúmeros estudos confirmaram que as proteínas recombinantes presentes nas plantas transgênicas usadas na produção de rações e outros alimentos não compartilham homologia significativa de seqüência de aminoácidos com proteínas alergênicas conhecidas (Delaney et al., 2008).

Os alérgenos das proteínas de alimentos são geralmente estáveis na digestão péptica e tríptica, e nas condições de acidez do sistema digestivo humano, de modo que podem chegar a passar através da mucosa intestinal para gerar uma resposta alergênica. Neste sentido, estudos com as proteínas recombinantes introduzidas nestes transgênicos são facilmente degradáveis no fluido digestivo, minimizando a possibilidade de serem absorvidas pela mucosa intestinal ao serem consumidas (Astwood, 1996).

Rotulagem de alimentos transgênicos - A informação adequada na rotulagem de produtos de qualquer natureza é direito do consumidor e deve ser feita de acordo com normas técnicas claras e conscientes. Entretanto, deve-se ter o cuidado de exigir informações de forma que sua implantação, sua fiscalização, sua efetividade e seu custo sejam viáveis, tanto para as agências de fiscalização e controle como para o principal interessado, que é o consumidor. Os custos de análise de alimentos contendo derivados de OGM são altos, onerando no preço do produto final.

A rotulagem dos alimentos derivados de OGMs que não contem o DNA ou a proteína exógena em sua constituição tem sido considerada desnecessária sob o ponto de vista de segurança alimentar. Um exemplo disso é o óleo de soja, canola, algodão, ou de qualquer outra origem, desde que sua composição seja a mesma do óleo convencional. Nos casos onde houver alteração da composição química, obrigatoriamente o consumidor deverá ser informado desta mudança.

Produtos derivados de animais alimentados com ração contendo OGM também não apresentam o DNA ou a proteína derivada do OGM em sua composição (Calsamiglia et al., 2007). Portanto, se é altamente improvável a passagem do transgene funcional pela ingestão direta do alimento GM, menos provável seria pela ingestão de carne, leite e outros produtos derivados de animais que apenas ingeriram rações GMs (Bennett et al., 2004; Gay et al., 2005). Concluise que a carne e os produtos dela derivados não contêm o produto transgênico e não causam nenhum efeito adverso quando utilizados na alimentação prescindindo, portanto, da necessidade de identificação no rótulo, o que implicaria em aumento desnecessário no custo do produto. A identificação de frações mínimas de DNA em alimentos industrializados derivados de OGMs requer análises complexas em laboratórios de última geração. No Brasil, até o momento, existe um número limitado de laboratórios aptos a fazer este tipo de análise. Quanto mais baixa a porcentagem de OGM, mais sofisticadas e caras são as análises.

A rotulagem dos alimentos tem diversas funções. Entre elas informar sobre sua composição e propriedades. Além disso, ela garante ao consumidor o direito à informação para que ele possa escolher de acordo com suas preferências. Qualquer tipo de alimento, transgênico ou não, é submetido à avaliação de segurança antes de ter sua comercialização permitida. Os derivados de OGMs utilizados na alimentação são submetidos a avaliações químicas, nutricionais, toxicológicas, com base em protocolos rigorosos, reconhecidos internacionalmente por instituições de alta credibilidade, como FAO, OMS, cujos resultados são submetidos à avaliação criteriosa por especialistas (Lajolo \& Nutti, 2003).

No caso dos OGMs, o símbolo adotado no Brasil não cumpre esta função. É totalmente equivocado porque veicula a falsa idéia de risco e não é didático para o consumidor. Assim, parece que medidas de controle através da rotulagem em produtos derivados de OGMs, além daqueles já estabelecidos para os convencionais, são desnecessárias por não terem bases científicas e relação com a segurança desses produtos à saúde.

\section{Literatura Citada}

ASTWOOD, J.D.; LEACH, J.N.; FUCHS, R.L. Stability of food allergens to digestion in vitro. Nature Biotechnology, v.14, p.1269-1273, 1996.

BECK, E; LUDWIG G; AUERSWALD, E.A. et al. Nucleotide sequence and exact localization of the neomycin phosphotransferase gene from transposon Tn5. Gene, v.9, p. 327-336, 1982

BEEVER, D.E.; KEMP, C.F. Safety issues associated with the DNA in animal feed derived from genetically modified crops. Nutrition Abstracts and Reviews Series B: Livestock Feeds and Feeding, v.70, n.3, p.175-182, 2002.

BENNETT, P.M.; LIVESEY, C.T.; NATHWANI, D. et al. Assessment of the risk associated with the use of antibiotic marker genes in genetically modified plants: report of the working party of the British Society for Antimicrobial Therapy. Journal of Antimicrobial Chemotherapy, v.53, p.418-431, 2004.

BENVENISTE, R.; DAVIES, J. Mechanisms of antibiotic resistance in bacteria. Annual Review Biochemistry, v.42, p.471-506, 1973.

BEVAN, M.W.; FLAVELL, R.B.; CHILTON, M.D. A chimaeric antibiotic resistance marker gene as a selectable marker for plant cell transformation. Nature, v.304, p.184-187, 1983.

BORLAUG, N.E. Human population, food demands and wildlife needs. North American Wildlife and Natural Resource Conference, v.37, mimeo, 1972.27p. 
CALSAMIGLIA, S.; HERNANDES, B.; HARTNELL, G.F. et al. Effects of corn silage derived from genetically modified variety containing two transgenes on feed intake, milk production, and composition, and the absence of detectable transgenic deoxyribonucleic acid in milk in Holstein cows. Journal of Dairy Science, v.90, p.4718-4723, 2007.

CASTILLO, A.R; GALLARDO, M.R.; MACIEL, M. et al. Effects of feeding rations with genetically modified whole cottonseed to lactating Holstein cows. Journal of Dairy Science, v.87, n.6, p.1778-1785, 2004.

CHAMBERS, P.; HERITAGE, J. [2004]. Transgenic crops and antibiotic marker genes. AGRIPPA (FAO peer-reviewed electronic journal)

CHASSY, B.; EGNIN, M.; GAO, Y. et al. Nutritional and safety assessment of foods and feed nutritionally improved through biotechnology: an executive summary. Journal of Food Science, v.69, n.2, p.62-68, 2004.

CROMWELL, G.L.; HENRY, B.J.; SCOTT, A.L. et al. Glufosinate herbicide-tolerant (LibertyLink) rive vs. conventional rice in diets for growing-finishing swine. Journal of Animal Science, v.83, n.5, p.1068-1074, 2005.

DELANEY, B.; ASTWOOD, J.D.; CUNNY, H. et al. Evaluation of protein safety in the context of agricultural biotechnology. Food and Chemical Toxicology, v. 46, p. S71-S97, 2008.

DONKIN, S.S.; VELEZ, J.C.; TOTTEN, A.K. et al. Effects of feeding silage and grain from glyphosate-tolerant or insectprotected corn hybrids on feed intake, ruminal digestion, and milk production in dairy cattle. Journal of Dairy Science, v.86, n.5, p.1780-1788, 2003.

ERICKSON, G.E.; ROBBINS, N.D.; SIMON, J.J. et al. Effect of feeding glyphosate-tolerant (Roundup-Ready events GA21 or nk603) corn compared with reference hybrids on feedlot steer performance and carcass characteristics. Journal of Animal Science, v.81, n.10, p.2600-2608, 2003.

FAO/UNFPA. Expert Group Meeting on Food Production and Population Growth. Published in 1996 by the Food and Agriculture Organization of the United Nations. Rome. 1996.

FLAVELL, R.B.; DART, E; FUCHS, R.L. et al. Selectable marker genes: safe for plants? Bio/Technology, v.10, p.141-144, 1992.

FOOD AND AGRICULTURE ORGANIZATION OF THE UNITED NATIONS - FAO. The State of Food Insecurity in the World. 2004. 43p.

GAINES, A.M.; ALLEE, GL.; RATLIFF, B.W. Nutritional evaluation of Bt (MON810) and Roundup Ready ${ }^{\circledR}$ corn compared with commercial hybrids in broilers. Poultry Science, v.80, n.1, p.51, 2001 .

GAY, P.B.; GILLESPIE, H .S. Antibiotic resistance marker in genetically modified plants: a risk to human health? The Lancet Infectious Diseases, v.5, p.637-646, 2005.

HAMMOND, B.; LEMEN, J.; DUDEK, R. et al. Results of a 90day safety assurance study with rats fed grain from corn rootworm-protected corn. Food and Chemical Toxicology, v.44, n.2, p.147-160, 2006.

ICSU International Council for Science. Genetically modified foods for human health and nutrition: the scientific basis for benefits risk assessment. Trend in Food Science and Technology, v.14, p.5-8, 2003.

ILSI. Nutritional and safety assessments of foods and feeds nutritionally improved through biotechnology. Compr Rev Food Sci Food Saf, v. 3, n. 2, p.35-104, 2004. Disponível em:http://members.ift.org/NR/rdonlyres/27BE106D-B6164348 - A E 3 A - 091 D 0 E 536 F $40 / 0 /$ crfsfsv3n2p00350104ms20040106.pdf.

IPHARRAQUERRE, I.R.; YOUNKER, R.S.; CLARK, J.C. et al. Performance of lactating dairy cows fed corn as whole plant silage and grain produced from a glyphosate-tolerant hybrid (event NK603). Journal of Dairy Science, v.86, p.17341741,2003
JAMES, C. Global status of commercialized Biotech/GM Crops: 2008. Briefs n.39, ISAAA: Ithaca, 2008.

JAMES, C. Preview: global status of commercialized transgenic crops: 2002. Briefs n. 27, ISAAA: Ithaca, 2002.

KIM, S.H.; KIM, H. M., YE, Y.M. et al. Evaluating the allergic risk of genetically modified soybean. Yonsei Medical Journal, v.47, p.505-512, 2006

LAJOLO, FM.; DI CIERO, L Segurança alimentar de produtos alimentícios derivados de animais alimentados com OGM.ILSI Brasil Notícias, v.14, p.3-6, 2006.

LAJOLO, F.M.; NUTTI, M.R. Transgênicos, bases científicas de sua segurança. SBAN, 2003. 110p.

LASSEK, E.; MONTAG, A. Nucleic acid components in carbohydrate-rich food. Zeitschrift fur LebensmittelUntersuchung und-Forschung, v.190, n.1, p.17-21, 1990.

LEVIN, J. G.; SPRINSON, D. B. The enzymatic formation and isolation of 3-enolpyruvylshikimate 5-phosphate. The Journal of Biological Chemistry, v.239, n.4, p.1142-1150, 1964.

MACKENZIE, D.; MCLEAN, M. Who's afraid of GM feed? Feed Mix, v.10, n.3, p.16-19, 2002.

MANETTI, C.; BIANCHETTI, C.; CASCIANI, L. et al. A metabonomic study of transgenic maize (Zea Mays) seeds revealed variations in osmolytes and branched amino acids. Journal of Experimental Botany, v.57, p.2613-2625, 2006.

NAKAJIMA, O.; TESHIMA, R.; TAKAGI, K.et al. ELISA method for monitoring human serum IgE specific for Cry $1 \mathrm{Ab}$ introduced into genetically modified corn". Regulatory Toxicology and Pharmacology, v.47, n.1, p.90-95, 2007.

NAP, J.P.; BIJVOET, J.; STIEKEMA, W. J. Biosafety of kanamycinresistant transgenic plants. Transgenic Research, v.1, p.239249, 1992.

NICKSON, T.; HAMMOND, B Case Study: canola tolerant to Roundup herbicide. An assessment of its substantial equivalence compared to nonmodified canola. In: ATHERTIB, K. (Ed.) Genetically modified crops. Assessing Safety, Taylor and Francis, 2002.

OECD. Consensus document on general information concerning the genes and their enzymes that confer tolerance to glyphosate herbicide. Series on Harmonization of regulatory Oversight in biotechnology, n.10, 1999.

OKUNUKI, H.; TESHIMA, R.; SHIGETA, T. et al. Increased digestibility of two products in genetically modified food (CP4EPSPS and Cry $1 \mathrm{Ab}$ ) after preheating. Shokuhin Eiseigaku Zasshi - Jounal of Food Hygienic Society of Japan, v.43, p.68-73, 2002.

PADGETTE, S.R.; RE, D.B.; BARRY, G.F. et al. New weed control opportunities: development of soybeans with a Roundup Ready $^{\mathrm{TM}}$ gene. CRC Press Inc., v.4, p.54-84, 1996.

RIDLEY, W.P.; SIDHU, R.S.; PYLA, P.D. et al. Comparision of the nutritional profile of glyphosate-tolerant corn event NK603 with that of conventional corn (Zea mays L.). Journal of Agricultural and Food Chemistry, v.50, p.7235-7243, 2002.

SANDEN, M.; BERNTSSEN, M.H.; KROGDAHL, A. et al. An examination of the intestinal tract of Atlantic salmon, Salmo salar L. parr fed different varieties of soy and maize. Journal of Fish Disease, v.28, p.317-330, 2005.

SCHLÜTER, K.; POTRIKUS I. Anwendungsbeispiele für die gentechnik bei lebensmitteln, transgene nutzpflanzen. In GASSEN, H.G.; HAMMES, W.P. (Eds.) Handbuch Gentechnologie Lebensmittell. 1.ed. Hamburg - Behr Verlag, 1997.

SHIMADA, N.; KIM, Y.S.; MIYAMOTO, K. et al. Effects of Bacillus thuringiensis Cry1 Ab toxin on mammalian cells. Journal of Veterinary Medical Science, v.65, n.2, p.187191, 2003.

STANISIEWSKI, E.P.; HARTNELL, G.F.; COOK, D.R. Comparison of swine performance when fed diets containing Roundup Ready ${ }^{\circledR}$ corn (GA21), parental line, or conventional corn. 
Journal of Animal Science, v.84, n.1, p.319, 2001.

STORK, J.; TEAGUE, W.D. Flour for man's bread. Minnesota, University Minnesota Press, 1952. 382p.

TAYLOR, N.; FUCHS, R.; MACDONALD, J. et al. Compositional analysis of glyphosate-tolerant soybeans treated with glyphosate. Journal of Agricultural and Food Chemistry, v.47, n.10, p.4469-4473, 1999.

TAYLOR, M.L.; HARTNELL, G.F.; NEMETH, M.A. et al. Comparison of broiler performance when fed diets containing Roundup Ready ${ }^{\circledR}$ corn event NK603, parental line, or commercial corn. Journal of Animal Science, v.84, n.1, p.320, 2001.

TAYLOR, M.L.; HYUN, Y.; HARTNELL, GF.et al. Comparison of broiler performance when fed diets containing grain from YieldGard (MON810), YieldGard x Roundup Ready (GA21), nontransgenic control, or commercial corn.Poultry Science, v.82, p.823-830, 2003.

T AYLOR, M.L.; HARTNELL, G.F.; RIORDAN, S.G. et al. Comparison of broiler performance when fed diets containing grain from Roundup Ready (NK603), YieldGard x Roundup Ready (MON 810 x NK603), non-transgenic control, or commercial corn. Poultry Science, v.82, p.443-453, 2003.

TAYLOR, M.L.; ST ANISIEWSKI E.P.; RIORDAN, S.G. Comparison of broiler performance when fed diets containing roundup ready (event RT73), nontransgenic control, or commercial canola meal. Poultry Science, v.83, p.456-461, 2004.

TAYLOR M.L.; HARTNELL, G.; NEMETH, M. et al. Comparison of broiler performance when fed diets containing corn grain with insect-protected (corn rootworm and European corn borer) and herbicide-tolerant (glyphosate) traits, control corn, or commercial reference corn-revisited.Poultry Science, v.84, n.12, p.1893-1899, 2005.

USP. Seminário Internacional: Transgênicos no Brasil (USP, IUFST, ABC.), Pró-Reitoria de Cultura e extensão Universitária, 2005, 303 p.

WANG, Y.; LAI, W.; CHEN, J. et al. Toxicity of anti-herbicide gene (BAR) transgenic rice. Wei Sheng Yan Jiu, v.29, p.141142, 2000. (in Chinese)

WEHRMANN, A.; Van VLIET, A.; OPSOMER, C. et al. The similarities of bar and PAT gene products make them equally applicable for plant engineers. Nature Biotechnology, v.14, p.1274-1278, 1996. 